\title{
Indignación y compasión Sentires apropiados e inapropiados en la participación política de mujeres migrantes*
}

\author{
Indignation and compassion \\ Appropriate and inappropriate feelings \\ in migrant women's political participation
}

ROCÍO ANDREA CASTILLO**

\begin{abstract}
The main objective of this article is to analyze the process of emotional learning of migrant women during their process of becoming activists, focusing on the expression of indignation and the mobilization of compassion. Resulting from an ethnographic research conducted from 2014 to 2015 in the city of Austin, Texas, the text explores the uses, expressions and meanings of two fundamental moral emotions in collective action, which have not been studied much in a migration context. Investigate this intersection will allow us to problematize the understanding of them and that of the female experience in collective action.
\end{abstract}

Key words: moral emotions, collective action, migrant activists

\section{Resumen}

El objetivo principal de este artículo es analizar el proceso de aprendizaje emocional de mujeres migrantes en su devenir activista; se enfoca en la expresión de la indignación y en la capacidad de mover a la compasión. Resultado de una investigación de corte etnográfico, realizada de 2014 a 2015 en la ciudad de Austin, Texas, el texto explora los usos, expresiones y significaciones de emociones morales fundamentales en la acción colectiva, pero que han sido poco estudiadas en un contexto migratorio. Indagar esta intersección permite complejizar su entendimiento y el de la experiencia femenina en la acción colectiva.

Palabras clave: emociones morales, acción colectiva, activistas migrantes

\section{Introducción}

$\mathrm{E}$ n octubre de 2014, la Coalición por los Derechos de los Migrantes de Austin y algunas de sus organizaciones aliadas $^{1}$ fueron invitadas a participar en un foro de diálogo con las autoridades locales y regionales de la capital texana. La Coalición era una de dos organizaciones locales de base migrante cuyo principal objetivo era

\footnotetext{
* Artículo recibido el 07/03/19 y aceptado el 19/09/19.

** El Colegio de México, Programa Interdisciplinario de Estudios de Género-Centro de Estudios Sociológicos, Carretera Picacho Ajusco 20, col. Ampliación Fuentes del Pedregal, 14110 Tlalpan, cDmx <rcastillo@colmex.mx>.

${ }^{1}$ Organizaciones de la sociedad civil local y regional conformadas por activistas profesionales, en general estadounidenses con estudios universitarios.
} 
detener las deportaciones en su ciudad y su condado (Travis County). El foro, llamado S-Comm Forum, ${ }^{2}$ se llevó a cabo un jueves por la tarde en un auditorio del Centro Cultural Mexicoamericano, ubicado cerca del centro de la ciudad. En el contexto local, el foro adquirió relevancia al inaugurar un espacio de diálogo con el entonces alguacil del condado, quien, hasta ese momento, se había negado a conversar con el movimiento y públicamente se declaraba antiinmigrante.

Algunos meses antes del foro, la Coalición y organizaciones afines habían logrado que el Consejo y el alcalde de la ciudad suspendiesen el Programa S-Comm en Austin. Asimismo, consiguieron que la Corte del condado -autoridad máxima regional- apoyase a la ciudad en esta decisión. El alguacil era el único al que no convencían. Esto era grave pues, aunque la ciudad y el condado decidieran interrumpir el Programa, el alguacil detentaba control absoluto de la cárcel de la región, en la cual se detenía a las personas migrantes, que eran entregadas a las autoridades migratorias. Para restringir su poder, durante la misma época en que se efectuó el foro, la Corte del condado revisaba la posibilidad de hacerle fuertes reducciones al presupuesto de la cárcel y, por lo tanto, restringir sus actividades como centro de procesamiento migratorio. La negociación de esta posibilidad incrementaba la tensión entre el alguacil y el movimiento migrante local. La oportunidad de resolver esta situación mediante el diálogo directo era algo que habíamos estado esperando las organizaciones y quienes las respaldaban.

Los testimonios públicos de migrantes ante las autoridades (ya fuese el Consejo de la ciudad, la legislatura estatal $\mathrm{u}$ otros actores) eran una estrategia utilizada con frecuencia por las organizaciones migrantes en Austin. En razón de que la Coalición era la única organización de base migrante conformada por migrantes de primera generación, normalmente aportaba los testimonios para estos encuentros. Por tal razón, Daniel, un joven hondureño criado en Estados Unidos y director de la Coalición, y otros aliados no migrantes se encargaban de preparar a las migrantes activistas para estos testimonios públicos. Días antes construían con ellas sus testimonios: discutían qué aspectos de su experiencia como migrantes era importante resaltar, cuáles otros había que atenuar, qué demandas concretas debían expresar, así como el tono emocional con el que este mensaje debía ser transmitido. Muchas veces ellas anotaban el testimonio acordado durante estas sesiones para memorizarlo, sobre todo anticipándose a los nervios que sentían al hablar en público.

Antes de proseguir cabe mencionar que, aunque había un par de miembros varones en la organización, estaba mayormente conformada por mujeres migrantes, quienes, en términos de liderazgo y organización de actividades y eventos, eran más constantes y participativas. De hecho, durante mi estancia de investigación sólo había dos hombres que asistían de ordinario a las reuniones, sin embargo, rara vez se anotaban para participar públicamente (como en los testimonios) o para organizar alguna actividad. En esta ocasión se escogieron sólo un par de testimonios: el de Cristina y el de su hija Dalia.

Cristina, una mujer mexicana de rancho, como se identificaba a sí misma, era una integrante asidua de la Coalición. Ya era residente legal, pues un par de años antes su primer hijo nacido en Estados Unidos había cumplido los 21 años y la pidió. ${ }^{3}$ No obstante, tres años antes, cuando ni ella ni su esposo contaban con un estatus legal regular, él fue deportado a México quedándose sola a cargo de sus tres hijos: de 20,14 y 3 años. Aunado a esto, pocas semanas antes de la deportación, su hija Dalia fue diagnosticada con diabetes juvenil. Dalia, con dificultad para enfrentar su enfermedad y la deportación de su padre, intentó suicidarse (por suerte sin éxito). Desde entonces, Cristina participaba con gran energía para detener las deportaciones, al tiempo que hacía gestiones para traer a su esposo de vuelta. Cristina ya estaba acostumbrada a dar testimonios, pues su historia permitía mostrar las consecuencias tangibles que la política migratoria tenía, no sólo sobre las personas migrantes, sino también sobre los futuros ciudadanos estadounidenses como Dalia.

El formato del foro fue formal, en el podio se sentaron el alguacil, una abogada aliada del movimiento, el alcalde de la ciudad de Austin, el jefe de policía, el director de otra organización aliada y el director de la Coalición. Mientras tanto, el público miraba desde unas gradas que permitían una audiencia de poco más o menos 120 personas, la cual fue rebasada porque había gente parada a los lados. El diálogo fue menos

2 S-Comm es una abreviación utilizada para referirse a Secure Communities, una política gubernamental implementada a partir de 2009 a nivel federal, que permitía a las policías locales actuar como policías de inmigración, habilitando y agilizando los procesos de deportación en zonas no fronterizas.

3 Pedir a alguien se refiere a los trámites que hace un ciudadano estadounidense ante las autoridades migratorias para ofrecer estatus de residencia legal a familiares directos. En ese tiempo, pedir a los padres era sencillo, el trámite tardaba alrededor de seis meses, mientras que otros familiares directos, como hermanos y hermanas, podían estar en lista de espera por más de una década. 
fructífero de lo anticipado: el alguacil se expresó poco y las intervenciones por parte de los representantes de las organizaciones eran ya conocidas. Pese a esto, el foro siguió como estaba planeado y tras las intervenciones de la mesa principal se ofreció la palabra al público; éste era el momento en el que se presentarían los testimonios de Cristina, Dalia y otras personas interesadas de la audiencia. Cristina pasó al frente y tomó el micrófono. Con todo y haber preparado su testimonio una noche antes con Daniel y otros afines a la causa, como me lo contó más tarde, se puso muy nerviosa y decidió expresarle al alguacil algunas inquietudes personales. El alguacil, un hombre afroamericano en sus cincuenta, escuchaba con sumo cuidado, aunque cada vez más contrariado. Cristina habló fuerte en español, con su tono norteño y directo, demandando compasión para los migrantes. Cuestionó su postura antiinmigrante y racista, siendo que él mismo, como una persona de color, sabía lo que era sufrir como lo había hecho su gente. Mientras Cristina hablaba se escucharon gestos de sorpresa y condena. El alguacil movía la cabeza en signo de reprobación y dejó de mirar a Cristina, desviando sus ojos hacia el suelo. Cristina, por su parte, siguió su discurso y reclamó que maltratara a los migrantes como los blancos habían maltratado a su gente. Al terminar su participación el alguacil se negó a dar réplica y dio por terminado el foro bajando del podio. Daniel salió a toda velocidad tras él para pedirle una disculpa en nombre de la organización.

La intervención de Cristina fue condenada por todos: por su hija, por las autoridades, por sus compañeras y por los líderes y aliados que la acompañaban. Se le dijo que había hecho las cosas mal, se habló a sus espaldas discutiendo tanto el mensaje como su personalidad. Fue una noche dura y que tuvo un costo muy alto para ella. Sin querer, había violado varios códigos sobre las dinámicas raciales y de género en las que estaba inmersa. Más tarde nos reunimos ella y yo para cenar en su casa: ninguna de las dos comprendíamos con exactitud qué había pasado; igual que ella, yo desconocía esos códigos. Algunos meses después, Jaqueline, una compañera de la Coalición, de origen mexicano, me aclaró las razones por las cuales ella y otras se habían molestado:

La manera, el tono en cómo lo manejó Cristina no me gustó. Fue... Siento que fue con mucha carga, con mucha tensión emocional, pero de mucho coraje que trae ella muy guardado. ¿Si te acuerdas? así como bien... Obviamente tenemos que tener... Hasta inclusive el tono, el modular la voz, con firmeza, saber lo que estás diciendo, pero sin dar a entender, sin ofender a la otra persona con tu..., porque a veces tú puedes decir "¡chinga tu madre güey!”, pero depende como lo digas, es como... O sea, te lo tomas relajado y dices "chinga a la tuya" o se agarran a trancazos, o mejor dices [en broma] "chinga tu madre", "y también la tuya" y seguimos cotorreando [Jaqueline, activista, migrante irregular, marzo de 2015].

Poco a poco entendí que para sus compañeras el principal error de Cristina fue no controlar sus emociones en público: había expresado mucha tensión emocional y coraje guardado por años. De hecho, Jaqueline no estaba en desacuerdo con el contenido del mensaje, sin embargo, intuía que existían ciertas reglas que como mujeres migrantes debían seguir, que el contenido tenía la misma importancia que el tono emocional con el que se expresaba, y que la asertividad del último dependía de quién lo enunciaba. En este caso, sostengo que Cristina había expresado demasiada ira, incluso venganza de acuerdo con Jaqueline, emociones que manifestadas por una mujer migrante no lograrían mover a la compasión. Como lo explicaré más adelante, la expresión de ira trastocaba la relación de poder establecida entre Cristina, una mujer migrante con un estatus legal precario, y el alguacil, un varón estadounidense con autoridad judicial.

A través de esta breve viñeta muestro cómo, en la negociación del poder, la dimensión emocional es una lente analítica enriquecedora en la comprensión de los mecanismos de perpetuación del control social, así

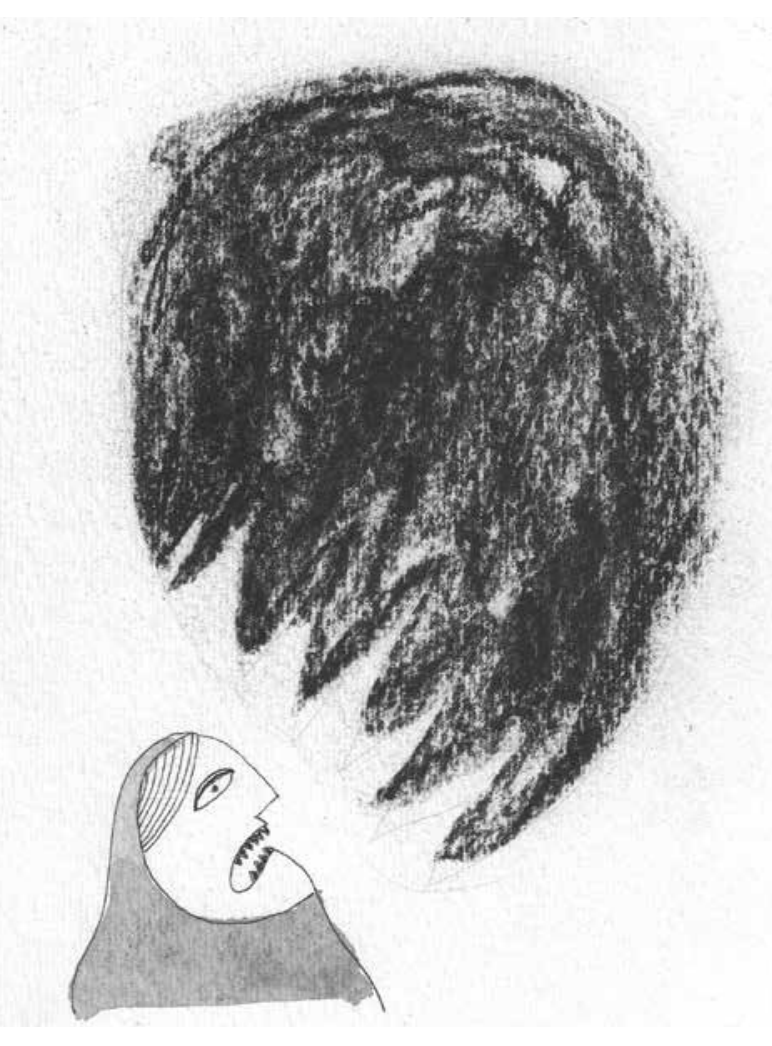


como en las estrategias y los dispositivos de resistencia puestos en marcha por las y los sujetos. En este artículo presento un análisis sobre la complejidad del aprendizaje emocional en la acción colectiva a través de las experiencias de siete activistas de organizaciones de base migrante en Austin, Texas. Dicho esto, el objetivo principal es escudriñar el proceso de aprendizaje emocional y subjetivo de siete mujeres migrantes en su devenir militante, enfocándome en dos emociones estratégicas de la movilización: la indignación y la compasión. Además, buscaré exponer la especificidad de significación de estas emociones en un contexto migrante, atravesado por el estatus legal y el género.

\section{Aproximación metodológica}

El análisis aquí presentado se basa en un trabajo de campo realizado de mayo del 2014 a mayo del 2015 y en el que se utilizó una metodología etnográfica y de entrevistas a profundidad llevadas a cabo con las activistas y otras personas involucradas en el movimiento por los derechos de los migrantes a nivel local. Mi objetivo es ofrecer una interpretación de este proceso de aprendizaje. En mi participación continua en las organizaciones tuve la oportunidad de tomar nota de los estados emocionales expresados en distintas situaciones y ante diferentes actores sociales; mientras que en entrevistas informales y otras a profundidad ahondé en la experiencia emocional y sus significados en la práctica militante. Mi participación con estas organizaciones (la Coalición y la University Leadership Initiative, ULI) tomó una función cercana a la de aliada voluntaria no-migrante, aunque difería de ella tanto por mi cercanía cultural con las participantes (todos los demás voluntarios eran estadounidenses) como por mi condición legal de investigadora visitante en la Universidad de Texas. Ser mexicana, igual que las participantes de la investigación, dio lugar a un rapport y a una cercanía afectiva que facilitó el que habláramos de las emociones y de sus experiencias en cuanto mujeres migrantes y activistas.

Para dar un panorama general de ambas organizaciones, basta decir que las dos estaban conformadas por migrantes de primera generación con estatus legales precarios, sobre todo de origen mexicano (aunque con alguna participación centroamericana), y una mayoría femenina. Las reuniones de la membresía eran semanales, y a veces bisemanales. Estas organizaciones se enfrentaban al reto de integrar un movimiento local de resistencia con una población sumamente vulnerable; no obstante, existía una coyuntura de la política regional y el sistema migratorio que abría espacios de participación y escucha en la arena pública local para mujeres migrantes (Castillo, 2017). Por ejemplo, Andrea, militante de uli, me explicaba que era más fácil que las demandas hacia las autoridades vinieran de una mujer en situación irregular que de un hombre: "I don't think I have never seen a man coming to uphold the story of coming to the US... because [...] most of them are like 'I' $m$ a single mom, I came to protect my children from their beating father' like that the story that I think appeals to a policymaker, but I don't think I have ever heard men" (Andrea, activista, enero de 2015).

Para aclarar este punto vale la pena mencionar que, en el ambiente político regional, la ciudad de Austin se presentaba a sí misma como el bastión demócrata y progresista del estado de Texas; lo cual resultaba en un reiterado interés por mostrarse abierta y tolerante de los buenos migrantes. ${ }^{4}$ Pero, al mismo tiempo que Austin estaba inmersa en las dinámicas nacionales de implementación de la política de control migratorio, y los hombres se encontraban sobrerrepresentados en los procesos locales de detención y deportación. La masculinización de la amenaza migrante tras el ataque terrorista del 9/11 y el crecimiento de economías postindustriales al nivel subnacional que requieren cada vez más fuerza laboral femenina en el sector de los servicios han tenido el efecto de que las mujeres migrantes hayan gozado de una relativa protección de las políticas de deportación, tanto en Austin como en otras ciudades de Estados Unidos (Golash-Boza y Hondagneu-Sotelo, 2013). En esta coyuntura, los hombres miembros de la organización se sentían mucho más vulnerables a participar de manera pública, e incluso a asistir a protestas pacíficas en el centro de la ciudad, pues era la zona donde se concentraba un mayor número de policías. En cambio, las mujeres encontraron un nicho de participación en el que se sentían relativamente seguras:

Y con todo lo que ha pasado después si te das cuenta de que aquí es, no más fácil, sino que de alguna u otra manera aquí te puedes ir a sentar a donde están trabajando todos los senadores y no te sacan a patadas [...]. Uno de ellos, no recuerdo el nombre de este señor, de uno de los demócratas: salimos de allí ya de noche, eran como pasadas de las 12 , iban a dar la 1 a. $\mathrm{m}$. y nos dicen que

\footnotetext{
4 Ésta es una interpretación basada en el análsis de la política migratoria de Austin encarnada en el programa público local Austin Welcoming City.
} 
fuéramos a su oficina porque habían mandado a traer pizzas. Entonces ver a nuestros hijos ahí hechos bola, todos durmiendo, escuchando, te diría muy atentos, pero ya todos cansados, yo estaba orgullosa [Jaqueline, activista, diciembre de 2014].

\section{Emociones apropiadas hacia el interior: apropiarse de la indignación}

La indignación ha sido una emoción muy trabajada en la literatura sobre movimientos sociales (Jasper, 2014), pues incita a la cohesión social, a la admiración y a un objetivo claro hacia dónde dirigir la ira colectiva (Castells, 2012; Jasper, 2014: 208). En términos teóricos, la indignación es una forma moral de la ira, ${ }^{5}$ que se experimenta ante la percepción de un daño no merecido - de acuerdo con una pauta moral, cultural e históricamente específica-hecho a uno o a un tercero. Por lo tanto, está íntimamente ligada a la percepción de la injusticia o la traición, y a aquello contendido como correcto/incorrecto en un momento histórico social determinado. En la práctica, la indignación es, entonces, una emoción que ayuda a construir un nosotros -los agraviados- y la distinción de esos otros -quienes producen o permiten el agravio-. Es en este sentido uno de los componentes afectivos del proceso de identificación colectiva (van Stekelenburg y Klandernmans, 2013). A pesar de esto, y como a lo largo de los siguientes subapartados describiré, sentir indignación en un contexto migratorio requiere un trabajo emocional mucho más complejo, el cual podría compararse con la ambivalencia emocional documentada por Gould (2001) en el movimiento de activistas LGBT (lésbico, gay, bisexual y transgénero) con VIH (virus de inmunodeficiencia humana).

En el caso concreto de estas organizaciones, los dirigentes expresaban una constante preocupación por ser capaces de enganchar a los miembros a la causa, es decir, conseguir mantener su interés y su participación. Daniel (director de la Coalición) compartió conmigo muchas veces esta inquietud, pues sentía que lograba entender cómo motivarlos de modo permanente. Sin embargo, yo encontré que él empleaba varias estrategias que, si bien no de manera intencional, eran hasta cierto punto sistemáticas. Una de ellas era utilizar el inicio de las sesiones para hablar sobre "los enemigos" y sus nuevos ataques. Estos "enemigos" podían serlo del movimiento (como el alguacil), de los migrantes (como el Partido Republicano), de los pobres (como el sistema capitalista) o de los pobres en América Latina (como los Estados Unidos). Por lo común se trataba de una narrativa basada en las injusticias y la hipocresía del enemigo.

Por ejemplo, en julio del 2014, el alguacil del condado de Travis asistió a una entrevista radiofónica en una estación de radio local de corte conservador,$^{6}$ donde, entre risas, planteó que no tenía ninguna intención de terminar su colaboración con el ICE (Inmmigration and Customs Enforcement), institución encargada de procesar, investigar y deportar a personas migrantes con estatus irregular. Subrayando, entre bromas y risas, percepciones estereotípicas y muy negativas de los migrantes, sobre todo de origen mexicano: que eran flojos, borrachos y poco confiables. Daniel llevó la noticia a la reunión de esa tarde, describiendo a detalle la entrevista y enfatizando la paradoja de que un hombre afroamericano utilizara estereotipos racistas para injuriar a otra comunidad (curiosamente, el mismo argumento que Cristina utilizó en su testimonio público). Daniel, utilizaba de forma sistemática estas narrativas para provocar indignación y un sentimiento de necesidad de lucha y unión entre la membresía.

\section{La ambivalencia frente a la indignación en un contexto migratorio}

No obstante, como ya he mencionado, sentirse indignadas no era siempre tan sencillo para las activistas. Yo sostengo que la culpa, asociada al ser una persona migrante con estatus legal irregular, era el principal obstáculo para alcanzar un estado de indignación constante. En la medida en que la indignación sólo se produce cuando un daño es percibido como no merecido (o injusto), si a la víctima del daño se le otorga alguna responsabilidad de lo acaecido es difícil que se produzca indignación. Laura, quien llevaba más de cinco años participando con la Coalición, me explicaba que para ella no siempre había sido fácil ser militante; en el siguiente testimonio es posible entrever la ambivalencia emocional que sentía entre exigir sus derechos (que entiende como universales) y hacerlo ante un Estado que no la invitó a venir:

\footnotetext{
5 "Las emociones morales [...] se refieren a los sentimientos de aprobación o rechazo basados en intuiciones o principios morales; asimismo están relacionadas con la satisfacción de hacer lo correcto (o incorrecto), y también con la de sentir lo correcto (o incorrecto), como por ejemplo la compasión en torno a los desamparados o la indignación frente a una injusticia" (Jasper, 2012: 50).

6 La entrevista se realizó el 4 de julio de 2014 en la estación de radio ultraconservadora KLBJ-AM.
} 
Mira, yo... yo lo que... entre muchas cosas de lo que ha promovido la Coalición y me ha enseñado [...] la principal es los derechos humanos, los derechos universales, tu derecho a la vida, tu derecho a la libertad, tu derecho a la educación y estando en un país que no es el mío, que no me invitó a venir, que yo decidí y escogí venir a vivir aquí. Me acepta entrar, porque legalmente me aceptó entrar, pero no a quedarme. Entonces eso es algo que yo lo tengo muy claro, por eso de alguna manera considero que soy una buena ciudadana, en el amplio sentido de la palabra porque estoy viviendo aquí, pero sé que he infringido [Laura, activista, enero de 2015].

Laura se sentía una transgresora; no olvidaba esto pese a llevar más de 15 años viviendo en Austin y más de cinco de participar políticamente. Su estatus migratorio irregular definía muchos aspectos de su vida, uno de ellos, la ambivalencia entre tener o no el derecho a exigir mejores condiciones de vida. Ser migrante irregular, con todo y considerarse una buena ciudadana, es encontrarse en la ambivalencia de actuar como ciudadana y ser una alien o una persona abyecta de la sociedad (Isin, 2009). Alejandra Aquino lo plantea como un "sentimiento de 'ilegitimidad estatutaria' definida como el sentimiento, difuso y virtualmente culpabilizante, que tiene el sujeto por no encontrarse en regla" (Aquino Moreschi, 2010: 417). Para Laura, como para otras activistas, la culpa de esa transgresión era, a veces, un obstáculo para lograr sentirse indignada.

En otra ocasión, Jimena, también integrante de la Coalición, me relataba su percepción de cuando acudimos a una de las jornadas de la Legislación estatal del 2015, en la que se discutía una propuesta de ley antiinmigrante. Jimena se sentía impactada por los testimonios antiinmigrantes presentados:

Híjole, pues está bien gruesa la situación, porque hay testimonios que son bien impactantes porque... en contra de los inmigrantes. Por ejemplo, los que yo vi ayer fueron muertes trágicas que, claro que eso no generaliza. No... a la comunidad inmigrante, pero bueno de un muchacho que estaba en un semáforo con su novia, [...] y llegó un carro y los impactó y mató a los dos muchachos, y era un indocumentado el que los chocó a ellos en el semáforo, entonces, híjole, claro que el señor se ve que tiene secuelas de trauma, como que... Estaba así, así como nervioso, como que movía mucho las manos, como que no tenía control... Y entonces estaba bien grueso porque el señor pienso que quedó así, [...] pero pues se le ve que es

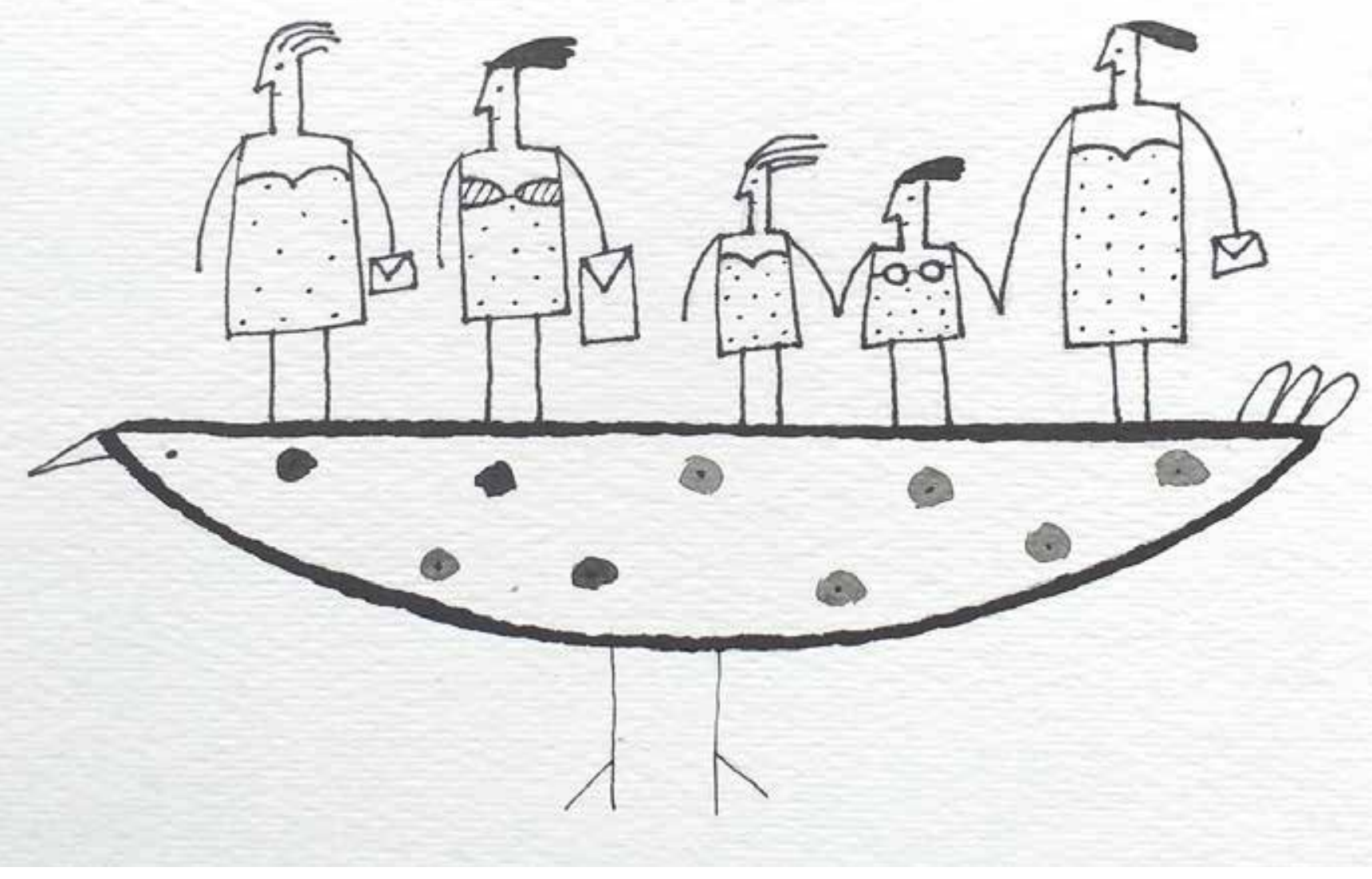


un nerviosismo total de desesperación, entonces híjole, qué fuerte. Y pues si eso le pasa mi hijo... es claro que tú te quedas en una situación pues de inconformidad contra todos, sobre todo porque estás en tu país y si alguien viene y hace esas cosas, pues sí es grueso [Jimena, activista, marzo de 2015].

El relato de Jimena muestra la ambivalencia emocional sobre la cual todas las participantes se definían como activistas: por un lado, reconocía el derecho a la inconformidad (como ella la llama) de estos ciudadanos, cuyos hijos habían muerto a manos de, o en un accidente en el que había un inmigrante con estatus irregular involucrado. Haciendo eco a lo planteado por Laura, Jimena recalcaba el sentimiento de injusticia vivido por los afectados cuando el culpable era un otro que viene a tu país y hace esas cosas, es decir, que viene sin haber sido invitado y tal vez deseado. La capacidad de Jimena y algunas de sus compañeras de lucha de aceptar estos argumentos como legítimos denota un sentimiento de culpa, de ser ésa a quien tampoco se le invitó a venir.

\section{Desplazar la culpa individual para poder sentir indignación}

Por otro lado, siguiendo el diálogo con Jimena, ella reflexionaba que esta situación, expuesta por los padres inconformes, no se podía generalizar para todos los migrantes irregulares, pues los migrantes también sufrían crímenes y accidentes sin recibir justicia por su estatus legal. Jimena estaba haciendo uso de historias que se contaban en la organización para provocar o avivar su sentimiento de indignación: desde un chico indocumentado que murió atropellado mientras caminaba sobre la acera a manos de un conductor que huyó de la escena del crimen, hasta del creciente número de albañiles indocumentados que morían o quedaban incapacitados por las malas condiciones laborales en las que trabajaban. Provocar y mantener la indignación dependía, entonces, no sólo de la construcción emocional e identitaria de "un nosotros", sino también de un continuo acceso y apropiación de lo que ellas llamaban: buena información. Ésta les facilitaba contrarrestar sentimientos de culpa y responsabilidad, y por lo general estaba integrada por datos históricos sobre la política económica global que, aterrizada en su propia experiencia (tanto migratoria como de género), permitía una apropiación que posibilitaba el desplazamiento de sentimientos de responsabilidad y culpa individual hacia condiciones estructurales sociohistóricas. En este sentido, una de las principales labores de los líderes formales de las organizaciones y los aliados era conseguirles buena información.

La narración de Andrea, ${ }^{7}$ autodenominada como una angry activist, me permite dar cuenta de este proceso. Aunque Andrea creció en Estados Unidos y tuvo acceso a educación formal (al momento de la entrevista estudiaba la licenciatura en la Universidad de Texas), durante su niñez y adolescencia no dispuso de información que le permitiese significar sin culpa su experiencia como migrante indocumentada. Andrea recordaba de un modo muy vívido la frustración que sentía frente a las carencias y las experiencias de discriminación que enfrentó durante la adolescencia. Esta frustración estaba dirigida sobre todo hacia sus padres, pues los responsabilizaba por haberlos puesto, a ella y a sus hermanos, en esa situación:

I started blaming them. I was like "we are only in the situation because...". At first I was like "no, it's not their fault", but then, when I started seeing other people around, I don't know, I started getting frustrated. And around when I was about to graduate and I'm like "so, all these... So, there is people with parents that have tried harder and they... and they don't have papers and they still made it, why? why?", and I said that to my parents several times. Oh my God I was a terrible child, terrible [Andrea, activista, diciembre de 2014].

Andrea culpaba a sus padres por haber transgredido las normas: haciéndola a ella merecedora del castigo de tener un estatus legal irregular. Durante mucho tiempo no comprendió la decisión migratoria de sus padres ni por qué se encontraban en una situación económica y social tan precaria. En la escuela no encontraba las respuestas, pues sólo se reforzaban estereotipos del sueño americano que idealizaban el trabajo duro como medio incuestionable para ser exitoso: si sus padres no tenían éxito era porque no se esforzaban lo suficiente. Con esta información Andrea sólo podía indignarse con ellos, pues la que sufría las injusticias resultantes de sus actos era ella; no tenía herramientas para sentir compasión por ellos, como se verá más adelante. No obstante, en la universidad, cuando comenzó a frecuentar las reuniones de ULI, escuchó por primera vez sobre el Tratado de Libre Comercio de América del Norte (TLCAN) y sus repercusiones para México y sus

7 Una activista de uli de generación 1.5, que llegó a los seis años a Texas. 
habitantes. Comprendió que detrás de su situación familiar había fuerzas estructurales e históricas que los habían empujado a tomar la decisión a migrar:

Now I always try to find a correlation, because then we can say like... I mean, it is kind of obvious: the reason that we are coming is because you have been pushing us to here. Because I had always been wondering... I wanted to find something to say [to anti-immigrant people] "there you go! ". Yeah, I mean I think about... every time since I learned about NAFTA I said "wait, it wasn't my parents' fault!" for a long time I blamed them [...] But I mean, even before them, my grandpa, I mean like it was kind of a generational thing, my grandpa would come. All the men of the little ranchito they all came. [...] My other grandpa, from my mother side, was in the Bracero Program. Which I just found out about, I didn't know! [Andrea, activista, diciembre de 2014].

A través de su narración, Andrea expone ese proceso de aprendizaje que le permitió una resignificación de su experiencia. Ahora dice: "I always try to find a correlation", lo cual le ayudó a entender que la culpa no residía en la decisión de sus padres, sino en un sistema político-económico injusto. Esto le provocó tanta indignación que pasó de querer estudiar negocios para mejorar su situación económica, a querer estudiar derecho y adquirir herramientas para transformar ese sistema. Aunque la decisión de migrar de sus padres era inalterable, la revisión de su pasado familiar le dio la pauta a una transformación subjetiva que le sirvió para desplazar la culpa de sus padres e instalarla en un sistema injusto, que ahora propiciaba su indignación y le abría la puerta a luchar junto con otros e incluso sentirse orgullosa de sus orígenes.

En la Coalición, el desplazamiento de la culpa individual resultó en la articulación de un sentimiento de indignación colectiva frente a la deshumanización: "Se nos está viendo como animales, no como seres humanos, se nos está viendo como un negocio redondo, [...] creo que seguimos en retroceso. No, no podemos avanzar como seres humanos, no podemos tener un valor como seres humanos y no nos están dando ese valor como seres humanos" (Cristina, activista, febrero de 2015). Esta deshumanización y objetivación del sujeto, que Cristina expresaba como que se les estuviese viendo como animales y como negocio redondo, eran metáforas potentes sobre su condición en el sistema político económico global. La buena información motivó esta reflexión y permitía habilitar un sentimiento profundo de indignación basado en la contradicción de migrar para mejorar sus condiciones de vida, pero únicamente a cambio de ceder la complejidad de sus necesidades como seres humanos (no sólo mano de obra). En consecuencia, la indignación ante estos hechos les daba herramientas para reconstruirse subjetivamente y reconocerse como seres íntegros, con derechos, que no pueden ser fragmentados, objetivizados, explotados e invisibilizados. Esta indignación las mantenía participando, construyéndose y reconstruyéndose como activistas organizadas.

\section{Los costos personales de mantener la indignación}

Aunque he mostrado el proceso de transformación de la culpa en indignación como un proceso esencial en el devenir activista de estas mujeres migrantes, éste no es un proceso lineal ni siempre emancipador. Sentirse indignadas todo el tiempo, en términos de mantener una ira constante, requería esfuerzo y tenía consecuencias emocionales y corporales en las militantes. Lo cual, a su vez, provocaba inestabilidad y dificultades para mantener la membresía de las organizaciones. Alberto Melucci, entre otros autores de la corriente de los nuevos movimientos sociales, planteó que la cultura y la identidad son dimensiones fundamentales para comprender el surgimiento y mantenimiento de la membresía de un movimiento social. Empero, se le prestó poca atención al papel que jugaban las emociones en esa amplia gama de procesos sociales y formas de acción que él definía como movimientos sociales (Melucci, 1991: 357), aunque estuviesen siempre implícitas. En este sentido, Jasper ( 1998 y 2014) plantea que entender el funcionamiento de emociones como la vergüenza, la decepción, la culpa y la frustración son fundamentales para comprenderlos. Otros estudios de caso han ahondado en emociones como el odio, los celos (Goodwin, Jasper, y Polletta, 2001) e incluso el amor y las relaciones libidinales (Goodwin, 1997) como emociones vinculadas al ocaso de un movimiento. Hasta ahora la indignación ha sido estudiada sobre todo como habilitadora de la movilización, sin embargo, vale la pena indagar el cansancio emocional que provoca. Aunque muchos estudios mencionan el fenómeno del burn out, yo hago una invitación para desmenuzar el proceso y experiencia emocional que lo compone (en este caso, sólo enfocándome en la indignación).

En las organizaciones migrantes este cansancio era discutido en charlas íntimas, alejadas de las miradas y oídos del resto de la membresía. Normalmente, estas charlas hacían referencia al agobio frente un nuevo precursor de la indignación. Por ejemplo, recuerdo una ocasión en que Ámbar, una de las integrantes más activas y veteranas de la Coalición, me contó, bajando 
la voz, aun cuando nos encontrábamos tomando un café solas, que había momentos en que se sentía harta de estar tan enojada. Que a veces sentía envidia de las personas a las que no les importaba nada, que se dejaban llevar por la corriente. Pese a las victorias que la organización había logrado ese año, Ámbar se notaba muy frustrada, y al bajar la voz denotaba miedo o vergüenza de admitirlo de manera abierta. Este cansancio emocional comenzó a ser evidente en las reuniones: un día, mientras se discutía la situación de la llegada de refugiados centroamericanos a la frontera sur de Texas, Ámbar declaró que tal vez deberían unirse a otra causa más alegre, una que sí movilizara al público, como el movimiento medioambiental. En ese momento nadie parecía haber puesto atención a su comentario, yo pensé que incluso había pasado como una broma, no obstante, algunos días después Cristina comentó con Daniel, y con un tono indignado, lo poco comprometida que se había vuelto Ámbar. Así, la indignación era un deber ser emocional activista que se vigilaba de modo sutil. Quienes no la mantenían (lo que se revelaba en la reticencia a participar públicamente, a hablar mal sobre algún "enemigo", o a encargarse de ciertas tareas en el interior de la organización, como decidir qué consignas traerían los carteles de una protesta pública) eran criticadas a sus espaldas y poco a poco marginadas (dejando de llamarlas para eventos a puertas cerradas o de pasarles información de primera mano). Estas prácticas de crítica y marginación tenían repercusiones irremediables: por ejemplo, no volvimos a saber más de Ámbar, y no fue ni la primera ni la última. Dejó la organización cortando todos los lazos que tenía con ella: no respondía el teléfono, los mensajes de texto e incluso se cambió de iglesia.

Antes de llegar a este extremo, las activistas utilizaban ciertas estrategias para gestionar el agotamiento emocional. Jimena y Laura, por ejemplo, se daban un tiempo, lo cual significaba tomar un descanso de su participación en la organización. Otras se volvían más selectivas en cuanto al tiempo y tipo de actividades que realizaban. Había quienes, como Abril, enfatizaban el lado social por encima de los objetivos de la organización; es decir, se enfocaban en organizar reuniones, fiestas o celebraciones para airear el ambiente, como ella lo decía. Ésta era su estrategia para mantenerse en la organización, lo cual había hecho por más de seis años. Cabe señalar que aquellas que aún no habían sentido ese agotamiento no veían con buenos ojos estas estrategias, y por lo general las interpretaban como una falta de interés y compromiso real a la causa. En contraste, quienes se sentían cansadas o frustradas percibían la actitud de las otras como una falta de sensibilidad. Hablando sobre este tema y sobre las cualidades de los líderes de la organización Jimena decía lo siguiente:

Una persona que... no solamente le interesas como miembro de su organización, sino que también le interesas en la parte personal, como el ser humano, no sólo tu trabajo. [...] Entonces, eso para mí era... yo creo que muy importante porque no necesita decirte la persona "ay es que me preocupo por ti”, sino que tú lo ves y tú lo sientes cuando a alguien no le interesas, sino solamente como miembro de trabajo, y no le interesas como ser humano [Jimena, activista, marzo de 2015].

Si observamos con cuidado, Jimena insinúa una reproducción de ese mismo sistema contra el que luchaban (un sistema al que no le interesas como ser humano, sino como miembro de trabajo). El cuidarse a sí mismas, Laura lo llamaba "ser coherente con una misma”, o enfocarse a organizar pequeños eventos sociales, era un modo de no sólo contrarrestar el agotamiento, sino también de construir una práctica política humanizante, siempre atada a la percepción completa o humana de sí y del otro; es decir, que no podía separarse del cuidado emocional y afectivo. Pero, claro, ésta es una dinámica siempre en tensión y en continuo cambio.

\section{Emociones apropiadas hacia el exterior: aprender a activar la compasión}

A partir de la experiencia de Cristina que inaugura este artículo es claro que la indignación, mas no todas las emociones exaltadas en el interior de la organización eran pertinentes hacia afuera. En ese caso, la indignación no lo era. La perspectiva estructural de las emociones (Kemper, 2006; Barbalet, 2004) nos permite explicar que la legitimidad de las emociones está dada por las coordenadas sociales en las que se encuentran los sujetos y el contexto de su expresión. La localización social de las personas migrantes en el contexto estadounidense imposibilitaba la legitimidad de la expresión pública de ira; a lo que se sumaba la complejidad de la condición de género, pues, como bien lo ha mencionado Jasper (2010), sólo el movimiento feminista ha ganado el privilegio de la expresión pública de ira femenina legítima. Las activistas iban aprendiendo, en la práctica, estas reglas del sentir, que rara vez eran explícitas. Las relaciones de poder en las cuales se encontraban inmersas reproducían, y a su vez eran reproducidas por, reglas emocionales que dictaban quién podía sentir y expresar qué, cómo 
y cuándo. En momentos en que buscaban ganar la compasión de sus escuchas sentían que mostrar su indignación frente a un sistema injusto no las llevaría muy lejos, o incluso les perjudicaría. Volviendo al testimonio de Cristina, Jaqueline precisó lo siguiente:

Como lo dijo era revancha por lo que ella... por lo que le quitaron a su marido, era una revancha lo que estaba diciendo; si ella sale con eso dices ¡no!, entonces la empiezan a ver... empiezan a señalar y dicen "ésos son resentidos". Empiezan a verte de otra manera, dicen "no es alguien que sea valioso para la comunidad, porque empiezan a dividir a la comunidad insultando a otra comunidad" [Jaqueline, activista, marzo de 2015].

Desde esta perspectiva, la indignación pública de Cristina, que se interpretó como un deseo de venganza, generaría una reacción en cadena en la que las activistas migrantes serían señaladas como resentidas y como poco valiosas para la comunidad. Por su cualidad moral, emociones como la indignación desafían, o por lo menos cuestionan, el statu quo de las relaciones de poder. De ahí que las activistas, reconociéndose en una posición desfavorable, apelasen a un sentimiento moral que permitiese mantener el statu quo de las

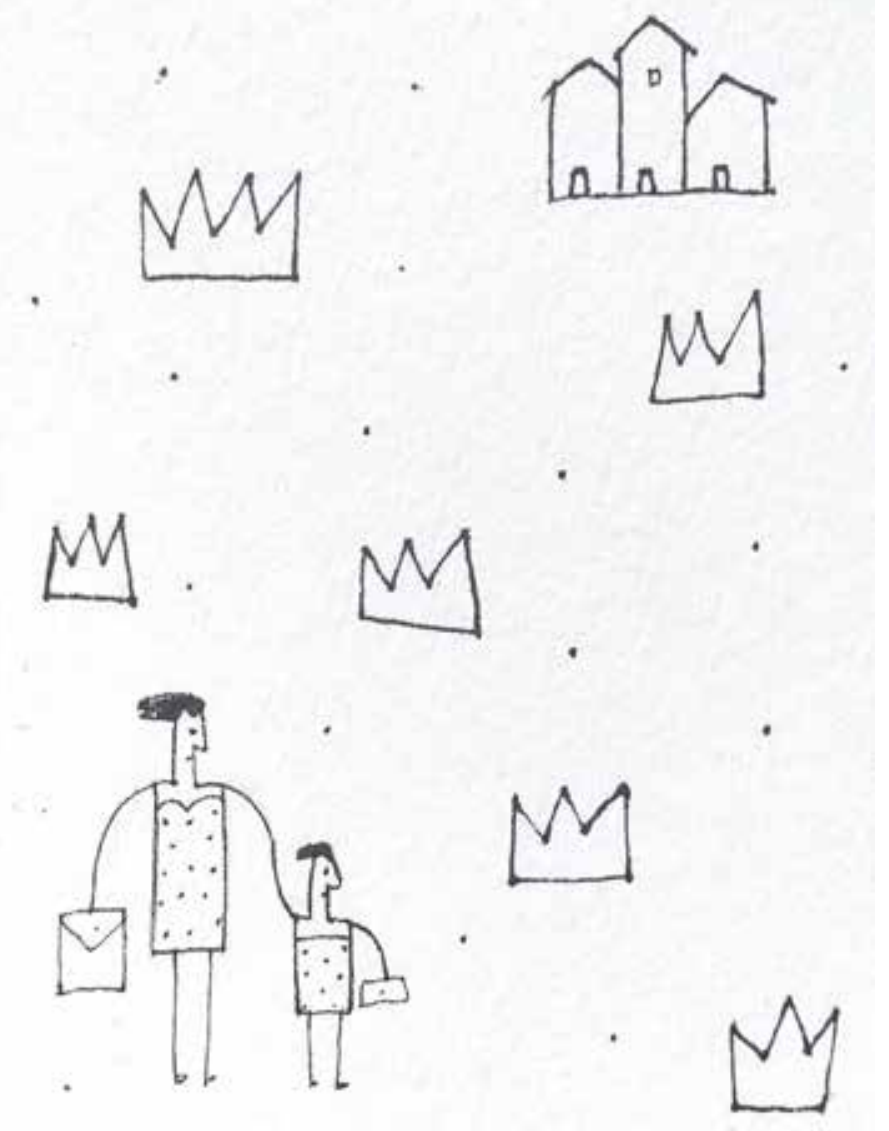

relaciones de poder: la compasión. No buscaban la empatía de un igual ante la indignación, sino la compasión de un superior ante su sufrimiento.

Compadecer, dice Schmidt Andrade, "es padecer junto al otro o con el otro, con su dolor que de alguna manera hago mío, al asumir que somos seres en relación" (2015: 288). No obstante, aunque compadecerse de otro significa padecer un dolor vivido en cuerpo o espíritu ajeno, por su carácter moral no todos los dolores o sufrimientos generan compasión. La compasión se da cuando se percibe que el compadecido sufrió una injusticia (valorada moralmente) de la cual no tiene responsabilidad o culpa; o cuando, en caso de ser culpable, las consecuencias rebasan aquello que el compadeciente considera como merecido. Este juego de coordinación de significados entre ambas partes produce intercambios en extremo complejos, que suceden en una trama de relaciones de poder, valores morales y reglas emocionales que Schmitt y Clark (2007) llaman "la micropolítica de la compasión” y que suelen reforzar relaciones de poder desiguales. Lo cual a su vez se refleja en la producción académica sobre el tema, pues la compasión como un objeto social se ha tendido a estudiar desde la perspectiva de aquellos que compadecen o de los llamados emprendedores de la compasión (Schmitt y Clark, 2007), pero todavía poco sabemos sobre aquellos cuyo objetivo es movilizarla para sí mismos.

Aprender a activar la compasión era un proceso importante y complicado, sobre todo porque, como el resto de las normas emocionales, era un aprendizaje más bien tácito. Sin embargo, en este proceso de aprendizaje, las activistas no eran sujetos pasivos y expectantes, sino agentes que examinaban los elementos, las expresiones, los recursos retóricos y los valores que interpelarían la compasión del otro, y no el rechazo, el enojo o el desprecio. Aprendían de los aliados y de migrantes crecidos en Estados Unidos las normas para hablar frente a las autoridades y para transmitir su mensaje de manera clara, directa y respetuosa. Ellos les ayudaban a organizar sus ideas y construir testimonios o historias fuertes -como ellas las llamaban- con mensajes impactantes, pero políticamente correctos.

Estas historias eran testimonios de la experiencia vivida y sufrida por una persona migrante. Eran fuertes, en cuanto que impactaban emocionalmente de manera positiva al escucha. Este impacto positivo sólo se lograba si la historia permitía expresar la expiación de la culpa a través del sufrimiento y mostraba al migrante como buen ciudadano, buena madre/padre, buen hijo, buen estudiante, etcétera. Apelar a la compasión a través de historias o testimonios fuertes era la 
estrategia más utilizada y con más relevancia para las activistas. Para ellas, esto significaba estar preparadas. Es decir, no sólo en relación con el contenido del mensaje, sino también con la forma de transmitirlo. Como planteó Jaqueline, un testimonio podía ser firme y respetuoso o vago y ofensivo, tanto por el contenido como por el tono y la emoción expresada. En este sentido se valoraba mucho la capacidad de algunas mujeres migrantes de primera generación, sobre todo de las profesionistas (mujeres migrantes con estudios superiores), por su facilidad de palabra para expresar estos mensajes del modo apropiado, como era el caso de Jaqueline, Jimena, Laura o Mónica. Sin embargo, este manejo impresionista del mensaje, sobre todo en términos emocionales, era mucho menos explícito, y se esperaba que las activistas conocieran la forma adecuada de actuar, lo cual generaba muchas confusiones y conflictos, pues las expectativas culturales y sociales de los distintos actores no siempre coincidían. Además de que no todas tenían esta capacidad de convertir su voz en una voz pública. En general, a las activistas les costaba trabajo superar el miedo y la timidez para hablar en público (Castillo, 2019), en parte porque no todas sentían que tenían una historia fuerte que transmitir.

\section{La micropolítica de la compasión hacia adentro y hacia afuera de las organizaciones}

En marzo de 2015 se inauguraron las sesiones bienales de la legislatura texana y las facciones más conservadoras intentaban promover varias leyes antiinmigrantes. La Coalición estaba pasando por una fuerte crisis interna y no había conseguido organizarse para presentar historias fuertes. A diferencia de las activistas migrantes, Daniel, director de la organización, no pensaba que la presentación de testimonios fuese eficaz, pues creía que esto era una estrategia obsoleta frente al cabildeo y las alianzas políticas a puertas cerradas. Las activistas se sentían defraudadas, ya que Daniel negaba su participación en el proceso y las habilidades que habían ido adquiriendo a lo largo de los años. En las muchas discusiones sobre el tema que tuve el privilegio de presenciar parecía que más que la eficacia de una u otra estrategia, lo que en realidad estaba en juego, para ellas, era la valía de sus competencias en la arena política. Es decir, su capacidad para afrontar la lucha en una arena política en la cual estaban en desventaja. Sus habilidades políticas eran, por consiguiente, habilidades emocionales: lograr conmover al escucha.
Pese a no ir oficialmente en grupo, como cada dos años, las activistas no faltaron a la sesión de la legislatura. Durante horas escucharon con atención el debate, turnándose para recoger a los hijos e ir a trabajar. No siempre comprendían todo, pues su inglés era limitado, sin embargo, se apoyaban para entender la dirección que tomaba la discusión. Durante las sesiones de participación de la comunidad los grupos antiinmigrantes también venían preparados con testimonios o historias fuertes (como la relatada por Jimena). Quienes deseaban organizar o dar su testimonio debían sortear el juego de coordinación de significados que se iba construyendo en el espacio, pues se trataba de una disputa emocional por la legitimidad del sufrimiento que, desde su perspectiva, inclinaría la balanza de las autoridades hacía compadecerse de unos o de otros. Por primera vez en varios años, las organizaciones migrantes no estaban preparadas para la legislatura. Ni la Coalición ni uli logró conformar un grupo de testimonios coherentes y consistentes. Las activistas estaban devastadas, pues sin el apoyo de otros, es decir, de aliados no migrantes, no se sentían capaces de prepararse para dar su testimonio. Ninguna, excepto Cristina, se atrevió a hablar sin el apoyo de su organización, que les ayudaba a construir un mensaje público apropiado.

Frente a la falta de testimonios, Cristina estaba ansiosa por dar el suyo, pero sus compañeras estaban renuentes. No decían ni sí ni no, simplemente no decían nada; expresando de un modo muy sutil su falta de apoyo. Un par de ellas me comentaron que lo que ella tenía que decir no era una historia fuerte que pudiese competir con las historias fuertes de los grupos conservadores. Argumentaban que su historia ya no era válida, pues los legisladores ya la conocían, pero sobre todo porque la conocían completa. Se referían a que el motivo de la detención del esposo de Cristina había sido la violencia doméstica. Tras su participación en el foro S-Comm, la experiencia de Cristina se había resignificado para el grupo: ahora se hacía evidente una carga de culpabilidad que no permitía activar la compasión: "y es que el de Cristina... mucha gente lo conoce $\mathrm{y}$, por ejemplo, si no lo conociera tal vez impactaría, pero el de Cristina ya lo conocen y lo conocen a fondo, toda la raíz, entonces no creo que... no creo que impactaría mucho" (Jimena, activista, marzo de 2015). Cristina no sólo había perdido la confianza de sus compañeras, sino además la legitimidad de su historia. La expresión pública de ira y revancha, como lo ponía Jaqueline, la habían cargado de responsabilidad y, por ende, consideraban que ya no motivaría la compasión necesaria, sino que incluso podría provocar rechazo. Mi percepción era 
que incluso ellas habían dejado de sentir tanta compasión por Cristina, lo cual redefinía las relaciones de poder en el interior de la organización.

Dado que para mover a la compasión no puede haber una atribución de responsabilidad y que el testimonio o la historia fuerte se vinculaba directamente con el imaginario del otro aceptable (es decir, del buen migrante), Jimena y otras activistas fueron poco a poco decidiéndose en torno al compadeciente ideal del contexto en el que se encontraban: el estudiante (ciudadano) hijo de inmigrantes.

Sobre todo, a los estudiantes que dependen de los papás, por ejemplo, hay estudiantes que son autosuficientes para pagarse sus estudios y que a lo mejor a los papás no los van a necesitar mucho, pero los estudiantes que por ejemplo necesitan a sus padres todavía para... que por ejemplo ellos no podrían seguir estudiando y que por ejemplo mi hija es ciudadana americana entonces lo que a ella le afectaría si sus padres se van. [...] Entonces, yo pienso que eso sería clave que los jóvenes tomaran iniciativa en ese tipo de testimonios para impactar. Porque ellos no toman en cuenta, casi la mayoría de los que yo vi ayer eran todos adultos, adultos ya grandes. Entonces yo siento que jóvenes que testificaran en lo que afectaría aparte, o sea su futuro y también la economía [Jimena, activista, marzo de 2015].

En términos del deseo de incitar a la compasión, las y los hijos de personas migrantes, traídos durante la infancia, libres de la culpa de la decisión de migrar, eran sujetos de compasión perfectos. Sin embargo, se reproducía un orden en donde las vidas y los cuerpos de las militantes migrantes con estatus legales precarios valían menos que aquellos con ciudadanía. Su protección se planteaba únicamente en relación con las personas con estatus regulares, es decir, con su vínculo productivo y reproductivo con ellos, pero no por su carácter en cuanto sujetas de derechos, o como seres humanos con potencia vital, como se manifestaba en el interior de la organización. En la coyuntura política de la organización y frente a un Congreso en manos de republicanos (a diferencia de lo que ocurría en la ciudad de Austin, mayoritariamente demócrata), las mujeres migrantes no encontraban el nicho que sí hallaban en el ámbito local. Sin discutirlo de manera explícita, todas reconocían que sus historias como mujeres migrantes (de buenas ciudadanas, como lo ponía Laura), no lograrían mover a la compasión. Frente a una legislatura mayoritariamente republicana, las mujeres migrantes con estatus legal irregular no se veían a sí mismas como sujetas de compasión.

\section{Palabras finales}

En mi caminar con estas mujeres aprendí que adquirir el conocimiento para ser activista no es cosa sencilla. El proceso de aprendizaje emocional en estas organizaciones es complejo y, aunque muchas veces emancipador, no está desprovisto de fallas, tensiones y muchas confusiones. En el caso particular del movimiento migrante, el estatus migratorio y la precariedad que éste supone atraviesan las dinámicas emocionales del movimiento, delimitando la legitimidad emocional de las activistas y de sus demandas. Por ejemplo, como he mostrado, la indignación en cuanto estado emocional que se construye hacia dentro de las organizaciones (que es, en sí mismo, un trabajo emocional arduo) y cuyo uso es fundamental para motivar la acción colectiva no ha ganado legitimidad en su expresión hacia el exterior (por la condición migratoria y de género de las activistas), todo lo cual generaba confusiones y tensiones en torno a la lectura que cada sujeto hacía de su contexto y posición social. En este sentido, el artículo pone de manifiesto la relevancia que tiene la dimensión emocional en la acción colectiva de estas mujeres, para quienes, sin gestionar su propio sentimiento de culpa (dado por un contexto geopolítico particular), sería muy difícil sentirse indignadas y, por lo tanto, con derecho a exigir un cambio de la política migratoria en el terreno local.

Asimismo, aunque yo he planteado (2019) que estas organizaciones son un espacio de subversión emocional o contienda sentimental, como lo nombra Besserer (2000), también son espacios normativos en los cuales se reproducen relaciones de poder. Al centrar la mirada en las emociones que se aprenden a movilizar dentro de una organización migrante, es posible analizar métodos "sutiles" de perpetuación del control social (como el aceptar la imposibilidad de que una mujer migrante exprese indignación públicamente ante las autoridades), y de resistencia (como la percepción que las activistas tenían de sí mismas como movilizadoras de la compasión en la arena política local), y no sólo los de subversión del statu quo (desde donde también es posible comprender la indignación). Todo lo cual a su vez nos permite pensar en las limitaciones y estrategias que los movimientos utilizan cuando se sienten forzados a dialogar con el Estado, como pasa en este contexto de acción colectiva migrante.

\section{Fuentes}

Aguino Moreschi, Alejandra

2010 "Entre luttes indiennes et 'rêve américain'. L'expérience migratoire des jeunes indiens 
mexicains aux États-Unis”, tesis doctoral, École des Hautes Études en Sciences Sociales, París.

BARBALET, JACK M.

2004 Emotion, Social Theory and Social Structure. A Macrosociological Approach, Cambridge University Press, Cambridge, $210 \mathrm{pp}$.

Besserer, Federico

2000 "Sentimientos (in)apropiados de las mujeres migrantes: hacia una nueva ciudadanía”, en Dalia Barrera Bassols y Cristina Oehmichen Bazán (eds.), Migración y relaciones de género en México, Grupo Interdisciplinario sobre Mujer, Trabajo y Pobreza/Universidad Nacional Autónoma de México-Instituto de Investiga-

Castells, Manuel ciones Antropológicas, México, pp. 371-389.

2012 Redes de indignación y esperanza, Alianza Editorial, Madrid, $157 \mathrm{pp}$

Castillo, Rocío A.

2017 "Subjetividades activistas migrantes y las emociones por el movimiento de los derechos de las personas migrantes en Austin, Texas", tesis doctoral, Centro de Investigaciones y Estudios Superiores en Antropología Social, México, 330 pp.

Castillo, Rocío A.

2019 "Timidez, género y movimientos sociales", en Debate Feminista, vol. 58, pp. 53-75.

GOLASH-BOZA, TANYA

y Pierrette Hondagneu-Sotelo

2013 "Latino Immigrant men and the deportation crisis: A gendered racial removal program", en Latino Studies, vol. 11, núm. 3, pp. 271 292.

Goodwin, JeFF

1997 "The Libidinal constitution of a high-risk social movement: Affectual ties and solidarity in the Huk Rebellion, 1946 to 1954", en American Sociological Review, vol. 62, núm. 1, 53-69.

GoOdWIn, JEFF, JAMES M. JASPER

y Francesca Polletta

2001 Passionate Politics: Emotions and Social Movements, University of Chicago Press, Chicago.

Gould, DEBOrah

2001 "Rock the boat, don't rock the boat, baby: Ambivalence and the emergence of militant AIDS activism", en Jeff Goodwin, James M. Jasper y Francesca Polleta (eds.), Passionate Politics.
IsIN, ENGIN F.

Emotions and Social Movements, The University of Chicago Press, Chicago, 135-157 pp.

2009 "Citizenship in Flux: The Figure of the Activist Citizen”, en Subjectivity, vol. 29, núm.1, pp. 367-388.

JASPER, JAMES M.

1998 "The Emotions of Protest: Affective and Reactive Emotions in and around Social Movements", en Sociological Forum, vol. 13, pp. 397-424.

JASPER, JAMES

2010 "Cultural approaches in the sociology of social movements", en Bert Klandermans y Conny Roggeband (eds.), Handbook of Social Movements Across Disciplines, Springer, Nueva York, pp. 59-110.

JASPER, JAMES

2012 "Las emociones y los movimientos sociales: veinte años de teoría e investigación”, en Revista Latinoamericana de Estudios sobre Cuerpos, Emociones y Sociedad, vol. 10, pp. 48-68.

JASPER, JAMES M.

2014 "Constructing indignation: Anger dynamics in protest movements", en Emotion Review, vol. 6, núm. 3, pp. 208-213.

Kemper, Theodore D.

2006 "Power and status and the power-status theory of emotions", en Jan E. Stets y Jonathan H. Turner (eds.), Handbook of the Sociology of Emotions, Springer, Nueva York, pp. 87-113.

Melucci, Alberto

1991 "La acción colectiva como construcción social”, en Estudios Sociológicos, vol. 9, núm. 26, pp. 357-364.

Schmidt Andrade, Ciro E.

2015 "Claves para una reflexión meta-antropológica sobre la compasión", en Síntese. Revista de Filosofía, vol. 42, núm. 133, pp. 279-295.

SCHMitT, Christopher S.

y Candance Clark

2007 "Sympathy", en Jan E. Stets y Jonathan H. Turner (eds.), Handbook of the Sociology of Emotions, Springer, Nueva York, pp. 467-492.

VAn Stekelenburg, Jacguelien

Y BERT KLANDERMANS

2013 "The Social Psychology of Protest", en Current Sociology, vol. 61, núms. 5-6, pp. 886-905. 